\title{
LOS DIÁlOGOS DE PAZ EN COLOMBIA. UNA MIRADA DESDE LA JUSTICIA DEL RESARCIMIENTO. ${ }^{12}$
}

\author{
Ángel Emilio Muñoz Cardona, $\mathrm{PhD}^{3}$ \\ Escuela Superior de Administración Pública de Medellín-Antioquia, \\ Colombia
}

\begin{abstract}
"Somos un animal muy feroz, somos un animal terrible nosotros los humanos, sea aquí en Europa, sea en África, en Latino América donde sea. Nuestra violencia es extrema. Nuestra historia es una historia de guerra, es una historia sin fin. Pero, somos la sal de la tierra”.
\end{abstract}

Sebastião Salgado.

Documental cinematográfico "La sal de la tierra” (2014).

\section{RESUMEN}

La finalidad del presente ensayo de investigación es reflexionar sobre la importancia de la preservación de la justicia en los diálogos de paz en Colombia que sirva a la construcción de un mejor país y de una mejor sociedad del postconflicto. Para lograrlo, se parte del concepto de justicia de resarcimiento del escoces Adam Smith y se asocia con el concepto del utilitarismo de John Stuart Mill como búsqueda de bienestar y de felicidad general. La investigación hace un recorrido cronológico de los acuerdos de Paz en Colombia y los compara con los alcanzados por otras sociedades del postconflicto en dos países de Europa y uno de América Latina. El ensayo concluye

1 [Recibido: 14/04/2016 Aceptado en su versión final: 17/11/16.]

2 Ensayo de investigación sobre el tema del Postconflicto y la Administración Pública desde el mes de julio de 2015 por el grupo Gobierno, Territorio y Cultura de la ESAP registrado en Colciencias en Categoría B.

3 Post-Doctor en Economía del Sector Público, Docente e Investigador de la Escuela Superior de Administración Pública de Medellín-Antioquia, <angel@esap. gov.co> 
en la necesidad de un Acuerdo de Paz respetuoso del derecho de las víctimas y de los territorios afectados por el conflicto armado. Un acuerdo que reduzca en lo posible los desencantos sociales, fortalezca las instituciones políticas y de justicia colombiana a futuro.

Palabras claves: Utilitarismo; justicia transicional; simpatía; perdón social y justicia social.

Clasificación JEL: H70, N40, N96, O15, P25, R50, K10, K33

\begin{abstract}
The purpose of this research paper is to do reflection on the importance of the preservation of the justice in the peace talks in Colombia for that serve the construction a better country and a better society of the post-conflict. To achieve it is necessary to revise the justice concepts of redress of Adam Smith and associate it with the concept of utilitarianism of John Stuart Mill as search for the general happiness. The investigation go to do a traceability exhaustive of the Peace Accords in Colombia to compare them with those achieved by other societies of the post-conflict in two countries in Europe and one from Latin America. The research conclude in the need of a peace agreement respectful of the right victims and territories affected by the armed conflict. An agreement to reduce as far as possible the not social satisfactions about Colombian political and justice institutions in the future.
\end{abstract}

Key words: Utilitarianism; transitional justice; sympathy; social forgiveness and social justice.

JEL Classification System: H70, N40, N96, O15, P25, R50, K10, K33

\title{
1. INTRODUCCIÓN.
}

Si se acepta el axioma "La justicia es el pilar fundamental en el que se apoya todo el edificio social” como afirma (Smith, 1997, p. 186). Y sí entendemos la justicia como el modo de evitar la respuesta resentida y no como una forma de evitar la reincidencia o ejemplarizar (Smith, 1995); entonces, ¿Cuáles son los costos sociales de la paz en Colombia si los exguerrilleros pasan a conformar partidos políticos sin pago de resarcimiento a las víctimas? Los diálogos de paz en Colombia entre 1991 y 2016 han dejado muchos sin sabores sobre 
condenas a delitos cometidos por lesa humanidad; ya que igualan el perdón social al perdón jurídico ${ }^{4}$ a través de apuestas públicas para la paz: "Perdón y Olvido" y "Justicia Transicional"5.

Las víctimas al ser de zonas apartadas de las grandes ciudades se ven forzadas a aceptar tales acuerdos de justicia sin castigo compensatorio que mitigue el resentimiento, con el fin de lograr la paz que beneficia al 85,6\% de colombianos ¿Cómo entender la paz y la utilidad social en Colombia si deja casi 7.000.00o de víctimas sin derecho de justicia y, peor aún, sin saber cuál ha sido la suerte de familiares secuestrados por años? De allí, que es objeto del presente ensayo mostrar la importancia de la justicia del resarcimiento en la construcción de una nueva sociedad del postconflicto; una sociedad en la que prime el derecho de las víctimas sobre el beneficio político de los actores armados.

El ensayo concluye en la necesidad de reducir los costos sociales implícitos en la construcción de la nueva sociedad del postconflicto. Una de las formas, es no permitir que desmovilizados que hayan cometido delitos de lesa humanidad pasen a conformar partidos políticos electorales o lleguen a ser líderes políticos: ediles, concejales, diputados, congresistas, alcaldes, gobernadores, embajadores y presidentes. De tal manera, que se preserve en la sociedad victimizada la confianza en sus instituciones de justicia a presente como a futuro.

El ensayo se ha dividido en cuatro partes. En la primera, se hace un recuento de los diálogos de paz en Colombia desde el año 1991 hasta el 2016. En la segunda, se definen los conceptos teóricos de la

4 Igualdad para la impunidad jurídica que no es avalada en la legislación internacional para delitos de lesa humanidad. Incluso, ni por la legislación interna de los países por intento de asesinato; piénsese por ejemplo, el caso del turco Ali Agca quien el 13 de mayo de 1981 atento contra la vida del líder político y religioso Juan Pablo II. Si bien el Papa visitó a su agresor en la cárcel y le perdonó, el agresor fue condenado a 29 años de prisión en Italia y en Turquía por intento de asesinato y asesinato a un periodista.

5 El Centro Internacional para la Justicia transicional define la justicia transicional como una respuesta a las violencias sistemáticas o generalizadas a los derechos humanos. Su objetivo es reconocer a las víctimas y promover iniciativas de paz, reconciliación y democracia. La justicia transicional es una justicia adaptada a sociedades que se transforman después de un largo periodo de violación a los derechos humanos. Para el caso colombiano desde hace 52 años, 1964-2016, conflicto que ha dejado más de 6.500.000 víctimas. Los programas de reparación consisten en una combinación de beneficios materiales y simbólicos para las víctimas, que pueden incluir desde compensaciones financieras hasta peticiones de perdón oficiales. 
simpatía y de la justicia como motores de la construcción del edificio social según la visión de los economistas y filósofos Adam Smith y John Stuart Mill. En la tercera, se hace un breve comparativo entre el utilitarismo y lo utilitario de los diálogos de paz en España, Irlanda, El Salvador y Colombia. En la cuarta parte se dan las conclusiones.

Para comenzar se hará una breve caracterización socioeconómica de Colombia de acuerdo a informes presentados por el Banco Mundial y el Departamento Administrativo Nacional de Estadísticas (DANE, 2015).

Según indicadores económicos del Banco Mundial para el 2015, Colombia posee un producto interno bruto de 377.7 billones de dólares, con un crecimiento promedio, a precios constantes, del 3,2\%. Posee 1102 municipios, de los cuales el 60\% son rurales con una población del 30,4\% del total nacional (48.228.00o). El sector agrícola aporta el 6,1\% al PIB y genera el 16,3\% del empleo (DANE 2015). El $6,17 \%$ de los municipios (68) poseen un desarrollo robusto. El 64,6\% de los municipios (712) poseen niveles de desarrollo intermedio (DANE 2015). El 29\% de los municipios (320) poseen un desarrollo incipiente (DANE 2015) y han sido víctimas, casi en su totalidad, del conflicto armado.

\section{INICIOS DE LOS DIÁLOGOS DE PAZ EN COLOMBIA.}

Eventos internacionales como la integración económica europea, la caída del muro de Berlín y la Perestroika afínales de los años 8os sirvieron de iniciativa a los diálogos de paz en Colombia, incluso fueron un gran estímulo en la sociedad colombiana para la aprobación de la reforma constitucional en 1991 como afirman (Bakke \& Peters, 2011, p.4; Guáqueta, 2007, p. 426). Entre 1989 y 1994 cinco de siete grupos guerrilleros existentes se desmovilizan, quedando por fuera las Fuerzas Revolucionarias Armadas de Colombia (FARC) y el Ejército de Liberación Nacional (ELN), afirma (Guáqueta, 2007). En 1999 el Gobierno Nacional reanuda los diálogos de paz dentro de una zona de distención de 42.000 kilómetros cuadrados; proceso que terminó con el fortalecimiento de la guerrilla en pie de fuerza y en recursos financieros a través de actividades ilícitas como el narcotráfico y el secuestro.

Desde el 2002 hasta el 2010 el Gobierno Nacional retoma el poder de la zona de distención y hace frente a la guerrilla, contrarresta 
sus acciones delictivas de narcotráfico y secuestro, ocasionando a las FARC y al ELN grandes bajas en sus filas.

Entre el 2003 y el 2006 se desmovilizaron 20 grupos de paramilitares y 31.671 combatientes. ${ }^{6}$ En el 2008 paramilitares desmovilizados pasaron a conformar bandas criminales emergentes en 17 departamentos y 152 municipios del país, financiándose con la extorsión, el secuestro y el narcotráfico a pequeña como a gran escala. ${ }^{7}$ En la actualidad, según informes de la Fiscalía General de la Nación en Colombia operan aproximadamente 1550 organizaciones criminales, en su mayoría de anteriores acuerdos de paz con paramilitares y de pandillas juveniles barriales.

En el 2012 el Gobierno Nacional buscó reanudar los diálogos de paz, sin embargo está se muestra difícil de lograr. Primero, por la alta descomposición social que afecta a más de la tercera parte de los municipios colombianos de actividad económica como la minera, hidroeléctricos, de producción de crudo y exportadores de banano, como se deduce del informe de investigación sobre el conflicto armado y el éxito económico de las empresas de (Camacho \& Rodríguez, 2012). Segundo, la alta descomposición política que ha permeado la administración pública y la democracia: la corrupción política, narco-política, para-política y filtración de guerrilleros en la rama del poder administrativo, como lo afirma (Chaparro, 2002, p. 109; Castaño, 2016). Tercero, la pérdida de credibilidad de los ciudadanos en sus instituciones de justicia.

No es posible que acciones democráticas como el voto popular sirvan de iniciativas para perdonar crímenes contra la humanidad, afirma (Guáqueta, 2007, p. 425). Las políticas del gobierno: Perdón y Olvido y Justicia Transicional no pueden hacer que la justicia pierda su función moral de administrar justicia. El perdón político no puede ser igual al perdón social, afirma el PhD en derecho (Herrera, 2005, p. 85-87). La política de beneficios a políticos corruptos, la falta de investigación y endurecimiento de castigo a militares acusados de delitos contra la humanidad y la ausencia de transparencia en la administración de justicia en Colombia dificultan el verdadero logro

6 Ver Archivo oficial de la Alta Consejería Presidencial para la Reintegración. "4 años transformando la vida de miles de colombianos": <http://web.archive.org/ web/20110921142311/http://www.reintegracion.gov.co/Es/proceso_ddr/Paginas/proceso_paz.aspx>

7 Ver página web del periódico El Tiempo. <http://www.eltiempo.com/archivo/documento/CMS-8931640> 
de alcanzar la paz, afirma en su página web institucional (Human Rights Watch, 21/12/2015). ${ }^{8}$

La paz en Colombia es posible: sí se moraliza la política y se reconstruye la justicia como principio fundamental para la existencia de una sociedad, como lo afirmará el escocés Adam Smith.

La nueva sociedad colombiana del postconflicto demanda la recuperación de los valores públicos perdidos por la descomposición política generada durante el conflicto armado por la narco-política, la para-política, la corrupción política, filtración de la guerrilla en la política, pandillas barriales y otros grupos armados dedicados a la economía ilegal de la extorción, chantaje y tráfico de estupefacientes a mediana y pequeña escala. Valores públicos que son cruciales para la conservación y fomento de la democracia y del buen gobierno, como lo afirman (Beck \& Bozeman 2007; Bevir 2010; Skelcher, Mathur and Smith 2005).

\section{A. ACuerdos relevantes de los dí́logos de paz deSDe el 2012.}

El 26 de agosto del 2012 el Gobierno de Colombia y las Fuerzas Revolucionarias de Colombia (FARC) firman el "Acuerdo General para la Terminación del Conflicto y la Construcción de una Paz Estable y Duradera", el 19 de noviembre de 2012 se dio inicio a los diálogos de paz en la Habana, Cuba.

El 26 de mayo de 2013, sin la participación de las víctimas, que en su gran mayoría son campesinos, Gobierno y FARC logran el pri-

8 Human Rights Watch en diferentes medios afirma: "El acuerdo de justicia es una acuerdo de impunidad" < http://www.eltiempo.com/mundo/ee-uu-y-canada/proceso-depaz-hrw-critica-acuerdo-de-justicia-del-proceso-de-paz-en-cuba/16464887> "El acuerdo de paz en Colombia es un cumulo de promesas vacías" < http://internacional.elpais.com/ internacional/2015/12/22/colombia/1450811785_717837.html> "Polémica entre Colombia y Human Rights Watch sobre el proceso de paz" < http://www.elmundo.es/internacional/2016/01/o8/568f122ee2704eec7b8b45ed.html> "Colombia: acuerdo con las FARC facilita impunidad de "falsos positivos" < https://www.hrw.org/es/americas/colombia> "Human Rights Watch criticó el aval al Marco para la Paz" < http://www.noticiasrcn.com/ nacional-pais/human-rights-watch-critico-el-aval-al-marco-paz> "HRW critica Acuerdo sobre Jurisdicción Especial para la Paz" <http://caracol.com.co/radio/2015/o9/24/ internacional/1443055342_992878.html> Y el 28 de marzo de 2016 "HRW denuncia impunidad para militares por "falsos positivos" < http://www.elcolombiano.com/colombia/ paz-y-derechos-humanos/hrw-denuncia-impunidad-para-militares-por-falsos-positivos-LX3819793> 
mer acuerdo sobre tema agrario, llamado: "Hacia un nuevo campo colombiano: reforma rural integral". Acuerdo, que pretende dotar de tierras suficientes a familias de campesinos con escases de tierra, planes en vivienda, agua potable, asistencia técnica, capacitación, educación, adecuación de tierras, infraestructura y recuperación de suelos, según COLPRENSA (26/05/2013).

Pero, ¿cuánto vale recuperar el agro colombiano? Es decir, hacerlo rentable para el campesino y su familia; en otras palabras, competitivo en productos para mercados internacionales. ¿Cuánto cuesta ofrecer los servicios básicos del Estado a todas las zonas agrarias olvidadas? Para revertir el daño político y social en las estructuras administrativas municipales, que por más de 30 años han generado las economías agrícolas de la ilegalidad, afirma Ospina (2016).

El 13 de junio de 2013 las FARC dejan claro que el proceso de paz no significa una entrega formal de las armas porque no está derrotada ni están desunidos. Los diálogos de paz son un acuerdo político de voluntades para el abandono de hostilidades y no de sometimiento.

El 28 de agosto de 2013 se aprueba el Marco Jurídico para la Paz sometido a examen por la Corte Constitucional el 25 de julio, aprobado en el Congreso de la República en junio de 2012. José Miguel Vivanco, señaló que el articulado "abre la puerta a la impunidad para guerrilleros, paramilitares y militares responsables de atrocidades" (Human Rights Watch, 2015). La razón principal, obedece a que delitos de lesa humanidad puedan quedar clasificados como delitos de carácter político, si se concede estatus político a las FARC. De igual manera, son los mismos guerrilleros quienes han elaborado sus propias leyes de condena. La ley permite beneficios a desmovilizados iguales al del ciudadano común en regla; tales como: acceder a cargos de elección popular y ser designados como servidores públicos, según lo afirma el Acuerdo sobre las víctimas del conflicto. (15/12/2015, p. 63).

El 6 de noviembre de 2013 se llega al segundo acuerdo de la agenda de los diálogos de paz entre las FARC y el Gobierno sobre la participación política de la guerrilla con plenas garantías. En este acuerdo, se deja leer que no hay restricción de ningún tipo para la participación política de los exguerrilleros, siempre y cuando reconozcan sus culpas e imploren el perdón social; por delitos, tales como: narcotráfico, secuestro, extorsión, ataques a la población civil con carros bomba, siembra de minas antipersonas y daños a la infraestructura pública. Los desmovilizados podrán participar en contiendas políticas y ser 
gobernadores o alcaldes electos mientras cumplen su condena, como lo ordena el Acuerdo sobre las víctimas del conflicto. (15/12/2015. p.p. 50-54).

El 3 de diciembre de 2013 el presidente de Colombia pide ante la Organización de Estados Americanos (OEA), flexibilidad por delitos de violación internacional a los derechos humanos, DD. $\mathrm{HH}$, en el marco del conflicto armado. Solicita la aplicación de Justicia Transicional "no se trata de sacrificar la justicia para lograr la paz, pero que la justicia tampoco se puede convertir en un obstáculo del proceso", como aparece registrado en las cronologías (Humanas Colombia, 2009-2016; Archivo de la Presidencia de la República 22/01/2014). ${ }^{9}$

El 16 de mayo de 2014 se logra el tercer acuerdo sobre cultivos ilícitos y narcotráfico. Acuerdo que gira sobre tres puntos básicos: sustitución de cultivos, programa de prevención del consumo y solución al fenómeno de producción y comercialización. En este acuerdo, se deja leer como parte de la justicia transicional: la no cárcel para guerrilleros, la no extradición, la amnistía por narcotráfico; ya que, el narcotráfico fue usado por la guerrilla para financiar la guerra política no el enriquecimiento personal de los líderes guerrilleros.

El 12 de mayo de 2015 el Consejo de Estado en Colombia afirma que las FARC no son un grupo terrorista. Son un grupo armado reconocido, por lo tanto y en concordancia con el Derecho Humanitario Internacional, DIH, no pueden ser catalogados como grupo terrorista (Humanas Colombia, 2009-2016). ${ }^{10}$

El 4 de junio de 2015 se establece el acuerdo para la creación de la Comisión de la Verdad. Para el 18 de octubre de 2015, según Comunicado Conjunto \# 62, se pone en marcha, unas primeras medidas humanitarias de búsqueda, ubicación, identificación y entrega digna de restos de personas dadas por desaparecidas. En segundo lugar, la creación de una Unidad Especial para la Búsqueda de Personas

9 Afirmación sobre justicia que también puede ser leída en la Intervención del Presidente en la tertulia "Los dividendos de la Paz" en Madrid. Alocución grabada por la Sala de Prensa en enero del 2014. Dirección web: <http://wsp.presidencia. gov.co/Prensa/2014/Enero/Paginas/20140122_o8-Palabras-Intervencion-Presidente-Colombia-Juan-Manuel-Santos-tertulia-Los-dividendos-de-la-paz. aspx $>$

10 El 29 de enero de 2015 se inician diálogos de paz con el Ejército de Liberación Nacional, ELN. Los beneficios alcanzados por las FARC también cobijan a guerrilleros del ELN. 
Secuestradas o Desaparecidas en el contexto y en razón del conflicto armado. ${ }^{11}$

El 29 de noviembre de 2015 el Jefe de negociación del Gobierno Colombiano expone los principios para alcanzar y mantener la paz, los cuales son: 1. El fin del conflicto armado es mediante solución política y no militar, la cual es larga y dolorosa. 2. Las víctimas presentes y futuras son la razón ética de los diálogos de paz. 3. La definición de justicia no se limita al castigo punitivo. Hay formas de justicia restaurativa que contribuyen a una más amplia satisfacción de los derechos de las víctimas. 4. La reparación a los 7.000.000 de víctimas en 52 años de conflicto armado es esencial. Simbólica, espiritual y también material. 5. El perdón es decisión personal, pero la sociedad no puede estancarse en el rencor, de allí que la paz es decisión que incumbe a todos los colombianos. 6. Participación política amplia. 7. La financiación de los acuerdos exige el aporte de todos, el cual a su vez es un incentivo para la cooperación internacional (Humanas Colombia, 2015).

El 15 de diciembre de 2015 se logra Acuerdo sobre las Víctimas. Acuerdo criticado por Human Rights Watch, porque el Tribunal Especial para la Paz aplicará un régimen de sanciones, que no reflejan los estándares internacionales aceptados sobre el castigo adecuado en abusos graves de lesa humanidad; y hacen que sea casi imposible que Colombia cumpla con sus obligaciones vinculantes conforme al derecho internacional de asegurar justicia por delitos de lesa humanidad y crímenes de guerra (Human Rights Watch, 21/12/2015). ${ }^{12}$

El 9 de marzo de 2016 el Congreso de Colombia acuerda reforma a la Ley 4ta de 1991 sobre Orden Público, por medio de la cual se faculta al Presidente la creación de zonas de concentración de exguerrilleros dentro del marco de acuerdo sobre Justicia Transicional. La reforma contempla: 1. Las zonas de ubicación de los desmovilizados son temporales. 2. No se ubicarán desmovilizados en zonas donde haya cultivos ilícitos y minería ilegal. 3. No se ubicarán en zonas de

11 Informe registrado por Caracol Radio "Gobierno y FARC logran acuerdo sobre desaparecidos”. Ver página web <http://caracol.com.co/radio/2015/10/18/ nacional/1445137053_778422.html>

12 El tribunal Especial para la Paz se ocupará de sancionar las graves infracciones al DIH cometidos por las FARC, ELN y agentes del Estado. En ellos se incluyen las 3000 víctimas de los "Falsos Positivos". Los "falsos positivos" son campesinos inocentes que fueron asesinados por el ejército (en presunto combate) acusándolos de guerrilleros. 
frontera ni urbanas de las grandes ciudades. 4. Las armas serán destruidas con verificación internacional (El Tiempo 09/03/2016). ${ }^{13}$

El 9 de abril de 2016 Gobierno y grupos guerrilleros buscan encontrar fórmulas jurídicas que les permitan hacer constitucional los acuerdos de paz alcanzados para la entrega de armas. De tal manera, que a futuro las condenas proferidas por delitos de lesa humanidad no puedan ser modificados por otros gobiernos.

El 23 de junio de 2016 el Gobierno Nacional y la Guerrilla de las FARC firman el acuerdo de paz, ponen fin a la guerra. El Gobierno Nacional creó 23 zonas rurales de extinción, las cuales sirven de transición para la vida civil del guerrillero y abandono de las armas. El plazo máximo para la entrega total de armas por parte de las FARC e inicio de la organización como partido político es de seis meses.

El 26 de septiembre de 2016 se firman los Acuerdos de Paz entre el Gobierno y las FARC. Para refrendar los Acuerdos se convoca a todos los colombianos el 2 de octubre de 2016 a un plebiscito nacional; con el fin de hacerlos constitucionales.

Para hacer constitucional dichos acuerdos, el Gobierno Nacional y la guerrilla se apoyan en los Artículos 3, 6 y 10 del Acuerdo de Ginebra, el cual permite a las partes definir las sanciones internas siempre y cuando no sean internacionales o no hayan afectado a otros países (Los Convenios de Ginebra, 1949, p.p. 37-40).

Pero, ¿cómo delitos de lesa humanidad como el narcotráfico, el secuestro y las minas antipersonas pueden no afectar otros países de manera directa o indirecta? Los acuerdos internacionales de beneficio comercial como el APDEA, las ayudas internacionales para el desminado de minas antipersonas, el tráfico de armas, las migraciones, los refugiados, los exiliados políticos, las remesas, las transferencias y el narcotráfico afectan economías de otros países. El secuestro con fines políticos y extorsivos de los grupos guerrilleros en Colombia han afectado la dignidad humana de nacionales y extranjeros, pero sobre todo al valor universal de la vida humana, como lo consagran

13 La guerrilla responde: "La Ley de reforma de orden público que aprobó el Congreso de la República son prisiones al aire libre, no son zonas de tránsito, sino campos de concentración Lo que proponemos son zonas de paso donde históricamente hemos coexistido con las comunidades, son áreas para implementar y promover el desarrollo". Tomado de <http://www.vanguardia.com/ colombia/350873-las-farc-cuestionaron-zonas-de-concentracion> Publicado por COLPRENSA, Medellín el 16/03/2016. 
los Artículos 5 al 9 del Estatuto de Roma de la Corte Penal Internacional (2002, p.p. 4-9).

El 2 de octubre se celebraron las votaciones del plebiscito, allí se les preguntó a los ciudadanos:

¿Apoya usted el Acuerdo Final para la terminación del conflicto y la construcción de una paz estable y duradera? Si o No

El 51\% de los colombianos dijeron NO apoyar el Acuerdo de Paz, el 49\% dijo SI apoyan los Acuerdos de Paz firmados el pasado 26 de septiembre.

El 16 de octubre de 2016 el presidente de Colombia, Juan Manuel Santos Calderón fue galardonado con el Premio Nobel de la Paz por sus esfuerzos. Gesto internacional para que la paz no se rompa, continúen los diálogos y se dé fin a 52 años de conflicto armado.

A mediados del mes de octubre de 2016 se inician diálogos de paz con el grupo guerrillero ELN, conversaciones que se han visto truncados por exigencias del grupo guerrillero de extradición de líderes presos en los Estados Unidos por narcotráfico y la no entrega de secuestrados, por ser rehenes confines políticos.

El 27 de junio de 2017 el Jefe de Antinarcóticos de la Corte Suprema de Justicia es denunciado por la DEA norteamericana por corrupción. La Corte Suprema de Justicia era usada para proteger a políticos y gobernantes corruptos a través del pago de cuantiosas sumas de dinero. Hechos que por ser un modo ordinario de proceso pusieron en investigación a expresidentes y magistrados de la Corte; lo que desmoraliza la creencia de la sociedad en sus instituciones de justicia porque atentan contra el Estado social de derecho al convertir la corrupción en forma de gobierno.

El 9 de septiembre de 2017 el Sumo Pontífice visitó a Colombia con el fin de contribuir al acuerdo de paz. La invitación del Papa fue el llamado al perdón social; restablecer el tejido social a través del perdón humanizado en la fe a Dios. El perdón social como bálsamo para el olvido e iniciador de una nueva sociedad del posconflicto.

El 14 de noviembre de 2017 la Unión Europea retira a las FARC de la lista de grupos terroristas, lo que, favorece las campañas políticas electorales de presidencia, senado y congreso a líderes del grupo exguerrillero en comicios del 27 de mayo de 2018 aún bajo investigación por delitos al DIH. El Decreto 903 de 2017 de extinción de los bienes de la FARC para el pago de indemnización de las víctimas, en el numeral 3.2.2.2., del Acuerdo Final (24/11/2016, p. 72), permite a 
las FARC usar gran parte de ese dinero en la creación de un centro de pensamiento y formación política que apoye al grupo político; lo que facilitará la financiación de las campañas políticas electorales de sus miembros a través de convenios.

\section{B. DECLARACIÓn de LOS PRINCIPIOS DE VíCtimas.}

Para dar cumplimiento al derecho de las víctimas, como base de la justicia, el Gobierno Nacional y las FARC crean el Sistema Integral de Verdad, Justicia, Reparación y No Repetición (SIVJRNR), la cual tiene como objetivos: la satisfacción de los derechos de las víctimas, el esclarecimiento de la verdad, la rendición de cuentas, la seguridad jurídica, la no repetición, la convivencia y reconciliación (Acuerdo sobre las víctimas del conflicto, 15/12/2015, p. 6).

El SIVJRNR estará compuesto por cinco mecanismos o medidas: Comisión para el esclarecimiento de la Verdad, la Convivencia y la No Repetición. Órgano que busca conocer la verdad, esclarecer las violaciones al DIH y promover la convivencia. La Unidad especial para la búsqueda de personas dadas por desaparecidas. Tiene como objetivo la búsqueda e identificación de todas las personas desaparecidas. La Jurisdicción Especial para la Paz. Incluye la Sala de Amnistía e Indulto y un Tribunal para la Paz. Encargadas de administrar justicia, perseguir y sancionar las graves violaciones a los DD.HH y al DIH. Medidas de reparación integral para la construcción de la paz. Satisfacer, indemnizar y restituir los derechos de las víctimas. Hacer reparación colectiva de los territorios, poblaciones y colectivos humanos afectados. Garantías de No Repetición. Acuerdos de cumplimiento para el fin del conflicto armado (Acuerdo sobre las víctimas del conflicto, 15/12/2015, p. 7).

Los integrantes de la Comisión para el esclarecimiento de la Verdad, la Convivencia y la No Repetición estará conformada por 11 personas postuladas por la comunidad y las organizaciones de víctimas; y serán seleccionadas por 9 integrantes del Gobierno Nacional y la guerrilla (Acuerdo sobre las víctimas del conflicto, 15/12/2015, p. 15). ${ }^{14}$

14 La delegación de los 9 integrantes que elegirán los comisionados no se conoce su distribución, cuántos del Gobierno y cuántos de la guerrilla. Tan poco se establece la profesión o nivel de conocimientos. Sólo se exige que sean personas de reconocida idoneidad ética, conocedores del conflicto armado, los DD.HH y el DIH. 
La declaración de los principios de víctimas establece que no serán objeto de amnistía ni indulto los delitos de lesa humanidad, el genocidio, los graves crímenes de guerra, la toma de rehenes u otra privación grave de la libertad, la tortura, las ejecuciones extrajudiciales, la desaparición forzada, el acceso carnal violento y otras formas de violencia sexual, la sustracción de menores, el desplazamiento forzado, además del reclutamiento de menores conforme a lo establecido en el Estatuto de Roma. (Acuerdo sobre las víctimas del conflicto, 15/12/2015, p. 28; Estatuto de Roma, 2002, p.p. 5-6). Dichos actos de violación al DIH durante el conflicto por los líderes de la Guerrilla y del Estado, serán castigados entre 5 a 8 años máximo, si son reconocidos por el acusado e implora el perdón social. ${ }^{15}$

La jurisdicción Especial para la Paz (JEP) establecerá a desmovilizados sanciones simbólicas o reparadoras al derecho de las víctimas. Las funciones reparadoras y restauradoras irán de cinco a ocho años. ${ }^{16}$ Comprenderán restricciones efectivas de libertades y derechos; tales como, de residencia y movimiento, que sean necesarias para su ejecución, según se afirma en el (Acuerdo sobre las víctimas del conflicto, 15/12/2015, p. 39; Castaño, 2016, p. 67). Según Acuerdo, ningún guerrillero desmovilizado puede pagar condena intramural, así se halle culpable de delitos de lesa humanidad.

Las funciones de reparación y de restauración, son proyectos sociales de desarrollo que los desmovilizados van a hacer en conjunto con la comunidad. Planeación y ejecución de proyectos de desarrollo social que sirvan al mejoramiento de la calidad de vida de las víctimas del conflicto en territorios específicos; el desmovilizado podrá desplazarse a la región, con la aprobación de la Jurisdicción Especial para la Paz, y participar con los líderes de la comunidad en la ejecución del Plan de Desarrollo con Enfoque Territorial para la Paz (Acuerdo sobre las víctimas del conflicto, 15/12/2015, p.p. 39-40). ${ }^{17}$

15 Las sanciones aplicables a los agentes del Estado, será decidida antes de la firma del Acuerdo Final de Paz; respetando lo ya establecido en la Justicia Especial para la Paz respecto a las sanciones propias, alternativas y ordinarias (Acuerdo sobre las víctimas del conflicto, 15/12/2015, Principio 61, p. 39)

16 Obsérvese que el Acuerdo de Víctimas habla de funciones reparadoras y restauradoras, no de sanciones punitivas. Lo que implica, que el desmovilizado goza de cierta libertad de movimiento y trato diferente al de un delincuente.

17 Los guerrilleros se comprometen a realizar funciones reparadoras y restauradoras en: obras de reconstrucción de infraestructura en territorios afectados por el conflicto, participación en los programas de limpieza y descontaminación de los territorios de minas antipersonal, municiones sin explotar o restos explosivos de 
Los subalternos desmovilizados y del Estado que hayan participado en delitos graves de lesa humanidad en cumplimiento de órdenes impuestas por sus superiores, deberán hacer funciones reparadoras y restauradoras entre dos y cinco años (Acuerdo sobre las víctimas del conflicto, $15 / 12 / 2015$, p. 39). ${ }^{18}$

Los actores del conflicto armado que hayan participado y no reconozcan sus culpas ni pidan perdón social; la privación efectiva de libertad no será inferior a 15 años ni superior a 20 años en el caso de conductas muy graves (Acuerdo sobre las víctimas del conflicto, 15/12/2015, p. 39).

La participación activa de los desmovilizados en el Plan de Desarrollo con Enfoque Territorial (PDET) es una estrategia que facilita la restauración del tejido social, el acercamiento entre infractores y comunidad, facilita el resarcimiento del delito y el acercamiento político electoral de los líderes desmovilizados. En otras palabras, facilita la inserción futura de los excombatientes a la vida política de las regiones como alcaldes, gobernadores, concejales, diputados, congresistas y presidentes.

\section{SIMPATÍA Y JUSTICIA, AXIOMAS DE LA FELICIDAD GENERAL.}

Ante la nominación al premio nobel de paz del jefe guerrillero Alias Timochenko en el 2015 y en el 2016 en la ciudad de Estocolmo, se valida a nivel internacional, de cierta manera, la acción guerrillera. La comunidad internacional valida o desconoce el drama que viven las familias de más de 2700 secuestrados desaparecidos, algunos por más de 20 años, como afirma María Clara (Ospina, 20/05/2015; 23/12/2015). ${ }^{19}$

guerra. Programas de sustitución de cultivos ilícitos, contribución a la búsqueda, ubicación, identificación y recuperación de restos de personas muertas o dadas por desaparecidas en el contexto y con ocasión del conflicto, y la participación en programas de reparación del daño ambiental, como por ejemplo la reforestación (Acuerdo sobre las víctimas del conflicto, 15/12/2015, p. 51)

18 Es notorio, que en el Acuerdo de Víctimas no se especifican sanciones para quienes incumplan funciones reparadoras y restauradoras; tan poco, se establecen condiciones de cumplimiento; lo cual, deja abierta la posibilidad de que puedan continuar gozando de los beneficios de la jurisdicción incluso irrespetando las condiciones impuestas por la Jurisdicción Especial para la Paz.

19 Se pregunta María Clara Ospina, columnista del diario El Colombiano del 20 de mayo del 2015: ¿Dónde están los más de 2.700 secuestrados de las FARC 
Si el utilitarismo se define en términos de Mill como aquella postura que considera que un acto es correcto cuando maximiza la felicidad general. La utilidad es, por lo tanto, consecuencialista, lo cual implica que no es intuitiva. Puesto que la utilidad se rige por el principio causa-efecto, subordina generalmente la teoría de lo correcto a la teoría del bien social; por consiguiente, el utilitarismo busca maximizar el bienestar general (Mill, 2002, p. 22). Lo que nos invita a preguntarnos, desde la visión positiva del utilitarismo clásico, ¿̇cómo lograr una justicia para el bien social?

El uso del secuestro como forma de enriquecimiento o medio de justificación política o medio de negociación por canje, no debería tener apoyo por ningún país del mundo, o empatía por ningún ciudadano del mundo, ni por ningún organismo internacional como mecanismo valedero de lucha; porque nos afecta a todos en el valor de seres humanos; porque cosifica al hombre, lo estratifica y le pone precio. ¿Qué es entonces la benevolencia universal?, ¿cómo se construye la felicidad general?, ¿cómo reconstruir los tejidos sociales afectados por la violencia? Preguntas que se hacen presentes en (Mill, 2002, p.22; Hauser, 2008, p.p. 18-19).

John Stuart Mill define el utilitarismo como búsqueda de bienestar general y define lo utilitario como búsqueda del redito personal (Troyer, 2003, p.p. xxiv-vi).

Para Mill, la felicidad que disfruta una sociedad es producto de conquistas humanas, es el fruto del desarrollo de las capacidades de autogobierno y de participación en la vida pública. No es el resultado de lo utilitario de las acciones políticas de un cuerpo de gobernantes, como lo pensaba Bentham, sino de las autorrealizaciones sociales; de la capacidad de autogobierno de cada ciudadano para bien de todos, como lo afirma (Muñoz Cardona, 2010, p.47).

El logro de aumentar la utilidad social depende de los sentimientos de simpatía, dice Smith, de la percepción de los ciudadanos de una situación. De las razones que tienen para aunar voluntades y trabajar juntos por el bien de todos y de cada uno. "Al percibir una situación, nos ponemos en el lugar del otro, y compartimos con él su placer o su dolor. Aprobar el motivo de una pasión, es considerarla

que aún no han sido devueltos? iDónde están! ¿Qué fue de ellos? ¿Por qué no se habla de este tema en las negociaciones de paz de La Habana? Parece que los negociadores, tanto los del gobierno como los de las FARC, pretenden que nos olvidemos de ellos. <http://www.elcolombiano.com/donde-estan-los-secuestrados-CN1953206> 
adecuada a su objeto, lo que equivale a simpatizar con ella", concluye (Smith, 1978, p. 3).

En otras palabras, se aprueba o reprueba un acto, no por la persona, sino por lo que él hizo o dejó de hacer. Si bien esta forma de proceder, es plausible y aceptado, como criterio de justicia, puede llegar a verse, en ciertos casos, como un sentir de inhumanidad, afirma Smith: tal es el caso, por ejemplo, del violador y asesino de menores que ha sido descubierto y es condenado a pasar el resto de su vida en la cárcel por delitos de lesa humanidad. Pero, sí pasado un año de reclusión se convierte al evangelio, mostrando verdadera transformación de arrepentimiento, invoca la piedad social e implora una nueva oportunidad en el nombre de Dios. Parece injusto no perdonar y brindarle una nueva oportunidad.

Ante situaciones como esta, afirma Smith: el orden jurídico no deberá retroceder y debe llevar a cabo lo sentenciado, bien por la simpatía adeudada a los dolientes que dejó sin sus parientes y reclaman justicia o bien porque el sistema de justicia no puede mostrar debilidad de carácter (Smith, 1997, p.p. 292-293); ya que serviría a otros como estrategia para salvarse de la condena proferida y por tanto, abrir la puerta a delitos más atroces. A pérdidas mayores en la credibilidad de la justicia, como también lo afirma Marc Hauser (2008, p. 19).

Las políticas públicas colombianas para el logro de la paz: Perdón y Olvido y de Justicia Transicional han indultado delitos atroces contra la humanidad; lo que beneficia a victimarios pero no a las víctimas. Hechos que socavan y desmoronan la credibilidad ciudadana en la justicia desde 1991 con los acuerdos de indulto a: paramilitares, narcotraficantes, guerrilleros y militares acusados de falsos positivos, afirman (Muñoz Cardona, 2014, p. 182; Castaño, 2016, p.58).

Sí la simpatía surge de la percepción de una situación, como lo plantea Smith, entonces, los individuos de una sociedad están obligados a realizar, desde su ética, un análisis objetivo de la situación que observa o percibe. Juicios objetivos donde se contemple, de manera imparcial, atenuantes o agravantes; lo que posibilita el actuar correcto en bien de toda la social, como afirma Marc Hauser una ética no natural, sino de evolución, una ética que evoluciona con la historia social del hombre (Hauser, 2008, p.p. 16-19).

De allí, que para Smith, la utilidad de la justicia no surge como forma de evitar la reincidencia o ejemplarizar sino como modo de 
evitar la respuesta resentida o el resentimiento (Smith, 1995) ${ }^{20} \mathrm{y}$, por tanto, el malestar social. De esta manera, la sociedad en su conjunto se protege a sí misma de su desintegración al no permitir la propagación de la injusticia o de la anarquía que producen los actos injustos y amañados a la voluntad particular.

Pero, ¿por qué el hombre debe actuar en conformidad con la sociedad y no en conformidad a su libre voluntad? Por el sentido de la moderación, de la pena o de la vergüenza. Afirma Smith, el hombre busca por naturaleza el reconocimiento y la aceptación social, lo que lo motiva a actuar conforme al temor de la sanción social y no del pecado (Smith 1997). No es la ética religiosa la que modera el comportamiento del hombre, sino más bien el sentido moral del reproche civil.

“...ninguna persona estará completa ni tolerablemente satisfecha, por haber eludido todo lo que sería reprochable en su conducta, salvo que al mismo tiempo haya eludido la culpa o el reproche de sí mismo" (Smith, 1997, p. 250). The prudent men avoid doing things that cause misfortune or schadenfreude, they do which is harmless to people (...) Do not you know that science more perfect, is the most sensitive at welfare and condition of the men? (Alighieri, 2014, p.p. 21, 43).

No basta con salvar la cara ante los demás, hay que lograrlo ante uno mismo; no basta evitar la vergüenza, sino además no caer en los sentimientos de culpa ante los resultados. Es decir, la sociedad es el espejo que corrobora lo que por cultura es aceptado. De allí, la importancia que tiene para los gobiernos atender la desmoralización social; evitar que el mal crezca y destruya el orden social alcanzado. Ese es el principal objetivo de las instituciones de justicia, tal como lo afirmó el filósofo inglés Francis Bacon en los Ensayos "La venganza es una especie de justicia salvaje, de tal manera que cuanto más se inclina la naturaleza humana para hacerlo, más necesaria es la ley para la eliminarlo "(Hauser, 2008, p. 145).

Es por ello, que no existen sociedades civilizadas sin justicia o sin el buen ejemplo de aplicación de la justicia. Las sociedades injustas son bárbaras e inaceptables, porque obligan a los ciudadanos a apo-

20 Se usan los apuntes sobre "Lecciones de Jurisprudencia" que hiciera un alumno en 1762, 1763 y 1766 de la catedra de Filosofía Moral y Lecciones sobre Retorica que impartía Adam Smith en la Universidad de Glasgow. 
yar con sus propios ingresos la existencia de gobiernos corruptos, inequitativos e inmorales (Hauser, 2008, p. 127; Castaño, 2016).

Para entender el planteamiento social que hace Smith a la justicia, es necesario entender el valor moral del resarcimiento como fundamento de paz y de conservación del orden social. Para Smith la justicia no depende de acuerdos políticos que benefician a grupos de líderes políticos, como los diálogos de paz en Colombia, sino del debido cumplimiento a los derechos del resarcimiento a las víctimas. Del reconocimiento plural que hace la sociedad en igualdad de trato a ciudadanos de regiones ricas y pobres, a campesinos y militares. El juez imparcial que habita en todo hombre, le obliga, por simpatía, a ponerse en la situación de la víctima y entender su reclamo. El fundamento de la justicia está en el reconocimiento de los daños causados a la víctima. Es decir, en la sentencia adecuada sobre el agresor.

El resentimiento del dañado, que incita a tomar represalias por el daño del ofensor, es la fuente real de castigo de los crímenes. Eso que Grotius y otros autores normalmente pretenden que es la medida original del castigo, es decir, la consideración del bien público, no explica suficientemente el establecimiento de los castigos (Smith, 1996, p.p. 5-7; 1995, p.p. 137-138)

Así pues, para Smith la justicia no se establece por la función de lo utilitario que beneficia a una mayoría frente a una minoría, sino por la compensación del agraviado. Por el debido resarcimiento. Lo que significa, fortalecer la justicia que beneficia a todos en sociedad; no permitiendo condenas injustas o el inconformismo por violaciones al justo derecho de las víctimas. El orden civil y social surge de la correcta aplicación de justicia, como lo sugieren Kaplow y Shavell, "La idea de que el castigo debe ser proporcional a la gravedad del delito es necesario si el objetivo del sistema de justicia es promover el bienestar de las personas en igualdad de condiciones" (Kaplow y Shavell, 2002, p. 328).

No se trata de una justicia basada en el "ojo por ojo", como lo afirma Smith; "esto es sin duda una costumbre bárbara e inhumana, y se ha dejado de lado en la mayoría de las naciones civilizadas" (Smith, 1995, p.p. 139-140; Hauser, 2008, p.p. 140-142). EL origen de la pena se debe más a un daño moral que a uno físico. Se refiere al resentimiento adeudado a familiares y amigos por su perdida; al desprecio moral hecho a la víctima por parte de un criminal.

Las emociones de sufrimiento o de dolor, de pena y resentimiento, requieren más del consuelo de la empatía y del acompañamiento; 
bien demandado justicia desde lo civil o bien desde la más simple sanción moral, como: ignorar y despreciar al agresor. No es igualando los derechos políticos y sociales del delincuente con los del ciudadano en regla, como lo intenta establecer la política de justicia transicional en Colombia en el marco de los diálogos de paz (Acuerdo sobre las víctimas del conflicto, 15/12/2015).

Por lo tanto, aquellos comportamientos que sólo buscan lo utilitario o el beneficio propio, sin importar el de todos los demás, son comportamientos que desmienten la verdadera naturaleza del ser social. Es así como, para que existan los valores públicos de la justicia y de la responsabilidad; todos los ciudadanos deben ser tratados iguales ante el incumplimiento de la ley, lo que protege la calidad de vida y el buen vivir en sociedad. Debe existir el buen ejemplo. Sí el militar y el guerrillero han cometido delitos de lesa humanidad deben ser sancionados con la misma severidad.

Sí un líder político es acusado de corrupción, por apropiación indebida de recursos públicos para educación y salud, deberá pagar con mayor severidad que aquel que roba un banco. Si el monto robado da 10 años de cárcel, ambos deben pagar el mismo tiempo de cárcel, sin favoritismos. Y sí, por falta de recursos públicos en salud, muere algún ciudadano por no haber recibido la debida atención hospitalaria; el político corrupto deberá compadecer por los delitos de: traición a la confianza pública, asesinato en segunda instancia y robo.

No es posible que en la clasificación de la infracción, algunas personas están protegidas por el favoritismo político y son condenados con grandes beneficios de confort, como la casa por cárcel. Otros, por el contrario, no tienen los mismos privilegios. Dichas diferencias hacen de la política un vicio y no una virtud. Hacen de la justicia una institución para el beneficio de unos pocos y no para el bien de toda la comunidad (Castaño, 2016, p.p. 69-73).

\section{EL UTILITARISMO O EL BIENESTAR GENERAL Y LO UTILITARIO O EL BIENESTAR PARTICULAR EN LOS DIÁLOGOS DE PAZ.}

Los diálogos de paz en países como España, Reino Unido y El Salvador dejaron insatisfacciones sociales, unos lo fueron más que otros. Ellos muestran diferencias en las negociaciones del cese del conflicto armado, número de víctimas y duración de las hostilidades; lo que 
deja enseñanzas universales en la manera cómo se negoció el cese de hostilidades, miremos porque (Tabla 1).

Tabla 1: Grupos armados, número de víctimas y duración del conflicto.

\begin{tabular}{|c|c|c|c|c|}
\hline País & $\begin{array}{c}\text { Grupo ar- } \\
\text { mado }\end{array}$ & $\begin{array}{r}\text { Número } \\
\text { de víctimas }\end{array}$ & $\begin{array}{c}\text { Dura- } \\
\text { ción del } \\
\text { conflicto }\end{array}$ & Ideología \\
\hline España & ETA & 839 & 45 años & $\begin{array}{c}\text { Naciona- } \\
\text { lismo }\end{array}$ \\
\hline $\begin{array}{c}\text { Reino } \\
\text { Unido }\end{array}$ & IRA & 3.500 & 25 años & Identidad \\
\hline $\begin{array}{c}\text { El Sal- } \\
\text { vador }\end{array}$ & FMLN & 78.000 & 20 años & Políticos \\
\hline $\begin{array}{c}\text { Colom- } \\
\text { bia }\end{array}$ & FARC & 7.000 .000 & 52 años & No clara \\
\hline
\end{tabular}

Fuente: Centro de Estudios Económicos Regionales CEER de la ESAP. Se muestran las diferencias del conflicto armado en países con acuerdos de paz.

\section{A. Grupo armado ETA.}

ETA fue un movimiento de nacionalismo armado que propendía por el derecho a decidir del país Vasco, por el derecho a que la opinión Vasca sea respetada por los Estados Francés y Español. A lo largo de los 45 años del conflicto armado se causaron 839 víctimas mortales, de las cuales 527 fueron civiles y realizaron 84 secuestros, afirma (Fisas, 2010, p. 5).

El proceso de paz se logró con el apoyo de una gran mayoría de ciudadanos vascos, españoles y franceses que aceptan la política como medio de diálogo para los consensos, defensa y reivindicación de los derechos sociales y humanos. "Hoy la sociedad vasca avanza en el reconocimiento político con derechos y capacidades para decidir sobre su futuro, a ser consultada y a que su voluntad democrática es expresada y respetada" (Fisas, 2010, p.p. 9-15).

Después de 12 años del fin del conflicto armado, las investigaciones a organizaciones políticas y culpables de delitos de lesa humanidad durante la época del conflicto armado continúan y son sancionadas por el gobierno español. 
Hechos del proceso de paz que aumentan la confianza social de los españoles en sus instituciones de justicia, evita la conducta resentida de la población y la descomposición social. Incluso los líderes del movimiento vasco que fueron acusados de delitos de lesa humanidad no pueden participar en política, por el contrario ellos son investigados y condenados. En otras palabras, el utilitarismo o la felicidad general de la sociedad Ibérica han crecido.

\section{B. GRUPo ARMAdo IRA.}

Afirma Andrés Cotrina que el movimiento armado irlandés IRA no era religioso sino de identidad: los nacionalistas se sienten minoría en Irlanda del Norte y los unionistas se sienten minoría en el conjunto de Irlanda, es decir "doble minoría”, como afirma (Cotrina Acosta, 2013, p. 2). Conflicto armado por la identidad nacionalista y unionista que dejó 728 muertos y 2772 heridos en dos décadas y media (Cotrina Acosta, 2013, p.p. 2, 6). El fin del conflicto comienza con la Declaración de Downing Street de 1993, la cual proclama el derecho de los ciudadanos de Irlanda del Norte a la autodeterminación a través del referéndum, sí quieren ser parte o no del Reino Unido, según lo afirma (Cotrina Acosta, 2013, p. 5).

La sociedad británica e irlandesa demandó el desarme de las organizaciones paramilitares con verificación internacional. Exigían al ejército y paramilitares renunciar al uso de la fuerza o la amenaza para influir en el resultado del proceso de paz; solo debían recurrir a medios democráticos y pacíficos para modificar puntos en desacuerdo.

La sociedad del Reino Unido condenó de manera irrestricta todas las expresiones de violencia así fuesen de baja intensidad -amenazas, golpes, e insultos- (Cotrina Acosta, 2013, p. 8). Por su parte, el Gobierno Irlandés exigía la protección de los derechos humanos en conformidad a los acuerdos internacionales establecidos; ya que, ellos forman parte de la legislación internacional y no deben considerarse materia de regateo en los diálogos de paz, como afirma (Cotrina Acosta, 2013, p. 9).

La importancia del proceso de paz seguido en Irlanda y Gran Bretaña fue la protección a los derechos de las víctimas del conflicto. Ningún actor del conflicto armado pasó a ser líder político sin antes haber pagado sus penas. Todos los ciudadanos debían ser de igual manera protegidos y amparados por la ley. Hechos que permitieron 
a Irlanda ser una de las economías fuertes de la Unión Europea. Es decir, el utilitarismo o la felicidad general de las sociedades del Reino Unido crece.

\section{Grupo armado FMLN.}

El Frente Farabundo Martí, FMLN, fue un movimiento armado que luchó por el fin de la dictadura de los años 70s y el restablecimiento de los derechos políticos de los ciudadanos salvadoreños. Durante los 20 años de lucha armada se registraron 70.00o muertos y 8.000 desaparecidos. La falta de las libertades fundamentales, la represión, las desigualdades socio-económicas fueron el principal detonante de la guerra. Los diálogos de paz comienzan con una reforma agraria y constitucional: en el ámbito jurídico, militar, electoral y los derechos humanos. Reformas que ponen fin a la dictadura del gobierno como afirma (Fernández García, 2002, p. 7). ${ }^{21}$

Aunque la sociedad salvadoreña voto por los diálogos de paz, no fue capaz de exigir, a la mesa de negociación, condena a delitos de lesa humanidad; quizás porque el ejército nacional también era culpable. De igual manera, la sociedad salvadoreña tampoco le hizo seguimiento a los acuerdos de paz.

El Informe de la Comisión de la Verdad quedó reducido al olvido, porque el pacto de paz se tradujo en impunidad total. Del lado de la guerrilla hubo violaciones, aunque no fueron ni el 25\% de las cometidas por el ejército salvadoreño. Pacto de paz aprobado por la Asamblea Legislativa en la que fue enterrada toda posibilidad de justicia.

El grupo guerrillero FMLN una vez desmovilizado pasó a ser partido político; el cual busca ganar y disfrutar de los beneficios personales y partidistas de la política electoral. Veinte años de lucha del FMLN para transformar el sistema de desigualdad económica y social en El Salvador se redujo a una simple participación política electoral, afirma (Salgar Antolinez, 15/8/ 2015).

A los campesinos desmovilizados del FMLN el Acuerdo les dio tierra y US\$20.00o para trabajarla; pero en el 2002 la agricultura salvadoreña colapsó. Se consolido un modelo económico para las multinacionales, creció el comercio y aumentó la población de inmigrantes a Estados Unidos.

21 De las 35 atribuciones especiales que tenían las fuerzas armadas, solo se dejaron cuatro funciones para la seguridad nacional (Salgar Antolinez, 15/8/2015). 
El Salvador pasó de tener un agro exportador, a ser un país que vive en primer lugar de las remesas (Banco Central de Reserva de El Salvador, 2015). Es una economía con fuertes pérdidas de credibilidad en la justicia por los anteriores Acuerdos de Paz. Actualmente el narcotráfico y el lavado de activos alimentan la economía ilegal de las pandillas y la violencia callejera, como lo afirman (Salgar Antolinez, 15/8/2015; Coates y Jiménez, 2009, p.p. 8, 9, 21-28).

Los diálogos de paz del El Salvador enseñan que después de 24 años la sociedad del posconflicto no logró restablecer el tejido social por la marcada ausencia de justicia en los procesos de paz. Las instituciones de justicia perdieron credibilidad social, lo que hundió a la sociedad salvadoreña en un atraso económico y de desconfianza en la política electoral aún mayor.

No son las formas de la economía ilegal las que afectan a las economías de países en vías de desarrollo como El Salvador y Colombia sino la ausencia de transparencia y de responsabilidad en las instituciones de justicia.

\section{LOS COSTOS IMPLícitos DE LOS DIÁlogos DE PAZ EN Colombia.}

En conformidad con los acuerdos de paz en Colombia se matiza la incapacidad del Gobierno para imponerse sobre los alzados en armas, lo que facilita la injusticia y la impunidad jurídica de los alzados en armas sobre delitos de lesa humanidad, incluso por el marcado carácter político o partidista que han revestido los diálogos de paz.

Las campañas de votación para el referéndum del 2 de octubre del 2016 fueron principalmente partidistas, donde simpatizantes se miraron como amigos o enemigos de la paz, o militantes de un líder político y no como ciudadanos conscientes de las decisiones sociales que toman. Acuerdo de paz que se votó bajo el temor de las amenazas de guerra del grupo guerrillero y no bajo el sentimiento de libertad de elección para la construcción de un nuevo tejido social para la paz. Hechos que limitaron el sentimiento nacional de inconformidad como voto de solidaridad con las víctimas del conflicto armado.

Incluso ante la seguridad del triunfo de aprobación ciudadana a los Acuerdos de Paz, el 18 de febrero de 2016 las FARC abandonan la mesa de negociación en la Habana-Cuba e ingresan a la Guajira-Colombia, con más de 250 guerrilleros fuertemente armados y se tomaron la escuela de la localidad para hacer proselitismo político. El 
ejército y la policía no se les permitieron intervenir en las garantías de la seguridad ciudadana. El Gobierno Nacional condenó la incursión de la guerrilla y lo calificó como un "desafío a la institucionalidad del país". ${ }^{22}$ La Defensoría del Pueblo la calificó de violación al DIH por cuanto violó el artículo 13 del Protocolo II de Ginebra que rige los conflictos armados no internacionales, el cual confiere protección especial a la población civil y a sus instituciones (Revista Semana 15/03/2016; Castaño, 2016, p. 70).

Los diálogos de paz en Colombia No buscan mejorar la distribución social, sino el lucro y consolidación de las maquinarias políticas. Bajo el argumento de la financiación de los diálogos de paz el Gobierno Nacional vendió la empresa de servicios públicos ISAGEN a una firma Canadiense en el mes de enero de 2016, de igual manera, se amenaza la venta de la petrolera Ecopetrol. La privatización de empresas del sector eléctrico y de hidrocarburos a multinacionales, puede ser negativo al bienestar económico de todos los colombianos, ya que se pierde el patrimonio nacional empresarial, como lo afirma (Ospina, 13/02/2016).

Afirma la profesora de jurisprudencia Susan Rose-Ackerman, en una sociedad en la que impera lo utilitario, es decir, la maximización del beneficio individual por encima de la búsqueda del bienestar general es una sociedad enferma, porque dicha búsqueda egoísta pronto equivale a perderlo todo, es decir, tanto el lucro individual como social.

Si por ejemplo, la corrupción administrativa pública crece al punto de parecer incontrolable, entonces el Estado será incapaz de prestar los servicios públicos básicos, más elementales; por lo que para el ciudadano común será imposible salir a la calle sin riesgo de sufrir una violación a su integridad física: ser víctima de pandillas o ser secuestrado o ser objeto de chantajes y llamadas extorsivas (Rose-Ackerman, 2010). Es una sociedad, en la que la justicia puede corromperse, donde la policía llega al punto de ser inoperante; como afirma el politólogo Mauricio Merino:

Un sistema donde nadie está protegido por el marco legal, porque este se volvió negociable y sus servicios se ponen al servicio de los

22 Diario El Espectador (18/02/2016). "Es un desafío a la institucionalidad": Procurador sobre presencia de jefes de las FARC en la Guajira”. Redacción Judicial. Bogotá. <http://www.elespectador.com/noticias/judicial/un-desafio-institucionalidad-procurador-sobre-presencia-articulo-617448> 
mejores postores; donde emprender un juicio de la naturaleza que sea no consiste en formular interpretaciones y alegatos legales valiosos sino en comprar fiscales testigos y jueces. En el que acumular riqueza y poder, en contra de todo el sentido común, puede ser contraproducente, pues los ricos se vuelven un objetivo visible de la delincuencia organizada y los poderosos son chantajeados y amenazados para orientar sus decisiones hacia donde los más violentos desean. Un punto en el que ni siquiera ese grupo de depredadores, incluso lo más violentos y los más corrompidos están a salvo, pues ellos a su vez se encuentran en guerra con otros igual de violentos y corrompidos por el dominio del espacio y del territorio. Un punto, en fin, en el que cada nueva decisión "racional” basada en el más estricto egoísmo destinado a maximizar el beneficio de cada uno se convierte, literalmente, en la más completa estupidez colectiva (Merino, 2010, p.p. 40-1).

Ese es el costo implícito que pagan las sociedades donde se ha dejado corromper las instituciones de justicia, donde la maximización del beneficio no tiene un límite claro, y por tanto, se vuelve contra todos sus ciudadanos, donde la política ha perdido su carácter moral como hacedora del bien público y ha permitido que sea ejercida por delincuentes corruptos. Donde los valores públicos de la transparencia y de la responsabilidad se han corroído junto con el de la justicia.

Una sociedad donde nadie está seguro, ni el pobre ni el rico, una sociedad, en términos de Adam Smith, en desmoronamiento, porque adolece de justicia. Tal es el peligro social que aboca a la nueva sociedad colombiana del postconflicto, una sociedad que pierde la confianza en sus instituciones políticas y de justicia. Una sociedad de suma cero, de impunidad generalizada, donde los costos de faltar a las leyes son cada vez más bajos mientras que los incentivos para corromperse son cada vez más altos, como lo afirma (Rose-Ackerman, 2010). De allí que se afirme con Román Castaño, los diálogos de paz en Colombia han sido más el afán de lo utilitario de las maquinarias políticas que la búsqueda del bienestar general a través de una protección a las instituciones de justicia (Castaño, 2016). O como afirma la hipótesis del subdesarrollo de Daron Acemoglu y James Robinson: el subdesarrollo es una consecuencia de la falta de instituciones transparentes, es un problema de las economías de instituciones extractivas y no inclusivas (2012, p.p. 63-85; 225). 


\section{CONCLUSIONES.}

La desmovilización y la reinserción de los excombatientes a la vida civil tiene un gran costo implícito en lo económico y en lo político; pero el costo implícito más importante está en la construcción de una sociedad democrática para la paz. Es decir, en la construcción de un país sin exclusiones sociales; en otras palabras, con mejores oportunidades laborales, sin corrupción política, con un agro más diversificado, tecnificado y competitivo en la producción de bienes tipo exportación.

Para ello se necesita, un país con más apoyo a la investigación, pero sobre todo, menos clientelista y corrupto, de tal manera, que la violencia no continúe a través de la conformación de nuevos grupos ilegales con nuevas actividades ilícitas.

No es el narcotráfico, ni la corrupción política la fuente principal de la descomposición institucional en Colombia, sino la ausencia de justicia que se entremezcla con la carencia de valores públicos que obliguen a los políticos al cumplimiento de los pactos electorales. En otras palabras, el problema de Colombia es un problema de la ética social cada vez más grande.

Se estima que Colombia posee 1500 bandas criminales que se alimentan de la economía ilegal, afirma (Ospina, 12/09/2015) y se fortalecen con la debilidad de la justicia, la corrupción política y la descomposición de la ética individual; lo que se traduce en atraso e inequidad.

Colombia además de la paz con la guerrilla necesita restablecer la confianza en sus instituciones políticas y de justicia. Es necesario, por respeto a las 7.000.000 de víctimas, que los desmovilizados no puedan participar como funcionarios o servidores públicos (Castaño, 2016, p.p. 65-68). Es decir, no sean: embajadores, presidentes, gobernadores o alcaldes, ni senadores, ni congresistas, ni diputados, ni concejales, ni ediles y menos representantes de organizaciones sociales y comunales por todos los delitos de lesa humanidad que cometieron. Hecho que demanda de una sociedad solidaria consigo misma.

Frente a la inminente participación política y económica de los exguerrilleros en regiones afectadas por el conflicto armado, como medida de justicia reparadora; es necesario enseñar a las comunidades cómo elaborar planes de desarrollo comunitario para la paz. Cómo hacer veeduría a los recursos públicos de la localidad; de tal mane- 
ra, que los escasos recursos no se conviertan en fondos privados del clientelismo político y de los desmovilizados.

Una sociedad que conoce sus derechos y deberes para el manejo y disfrute de bienes públicos; que entiende, en términos de Robert Owen, la necesidad de trabajar unida en procura del bien general, alcanza más nobles ideales, mejora la distribución de la riqueza, afirman (Stigliz, 2002, p. 13; Fisk, 2004). Es una sociedad menos títere del egoísmo del mercado de bienes y servicios y del voto; menos propensa al fanatismo ideológico, al clientelismo político o religioso, como lo afirma (Muñoz Cardona, 2015, p.p. 63, 256-257).

Lo anterior implica, formar la sociedad en valores públicos; a través del consenso de lo que es bueno y conviene a todos; cómo conciliar el interés público y privado, cómo vender la idea de proyectos comunes, pregunta (Reynaers, 2014, p.p. 32-35). No es posible pensar la justicia y la solidaridad, es decir el bien social, sin primero formar a la sociedad en la conciencia política, en el reconocimiento del otro como igual, con los mismos derechos fundamentales de persona humana, es decir, si primero no se educa a la sociedad en la riqueza de los valores públicos, afirma Anna (Reynaers, 2014, p.p. 34-35).

La defensa de los bienes y recursos públicos son la base racional de las elecciones democráticas porque implican la construcción y elección de mejores planes de gobierno que benefician a toda una nación, región o localidad. Los planes de gobierno son la base ciudadana para el bienestar social y de calidad. Esta es la razón por la cual la sociedad apoya con su voto a líderes políticos comprometidos en la ejecución de obras públicas y políticas de bienestar general, afirma (Muñoz Cardona, 2014; 2015, p. 257).

\section{BIBLIOGRAFÍA.}

Acemoglu, Daron., \& Robinson, James. A. (2012). Por qué fracasan los países. Los orígenes del poder, la prosperidad y la pobreza. Colombia. Deusto, segunda edición

Acuerdo sobre las víctimas del conflicto. (15/12/2015). "Sistema Integral de Verdad, Justicia, Reparación y No Repetición”, incluyendo la Jurisdicción Especial para la Paz y Compromiso sobre Derechos Humanos. Borrador Conjunto: Gobierno y guerrilla. <http://equipopazgobierno.presidencia. gov.co/acuerdos/Documents/acuerdo-punto-victimas.pdf>

Alighieri, Dante. (2014). La divina comedia. Madrid: Mestas Ediciones. 
Archivo de la Presidencia de la República. (22/01/2014). "Los dividendos de la Paz". Bogotá: Sala de Prensa. Sistema Informativo del Gobierno, SIG. <http:// wsp.presidencia.gov.co/Prensa/2014/Enero/Paginas/20140122_08-Palabras-Intervencion-Presidente-Colombia-Juan-Manuel-Santos-tertulia-Los-dividendos-de-la-paz.aspx>

Banco Central de Reservas de El Salvador. (2015). Base de Datos Económica-Financiera. Ingresos Mensuales de Remesas Familiares 1991-2016. El Salvador. <http://www.bcr.gob.sv/bcrsite/?cdr=85>

Banco Mundial. (2015). Indicadores Mundiales de Desarrollo. Economía, Estructura de Producción. New York: World Bank. <http://wdi.worldbank.org/ table/4.2>

Bakke, E. \& Peters, I. (2011). 20 Years Since the Fall of the Berlin Wall: Transitions, State Break-up and Democratic Politics in Central Europe and Germany, United Kingdom, Cambridge: Intersentia Ltd.

Beck, Jorgensen and Bozeman Barry. (2007). "Public Values: An Inventory". Administration \& Society 39(3), p.p. 354-381

Bevir, Mark. (2010). Democratic Governance. Princeton, New Jersey: Princeton University

Camacho, A. \& Rodriguez, C. (2013). "Firm exit and Armed Confilct in Colombia", Journal of Conflict Resolution: Sage, Vol. 57 (1), pp. 89-116

Chaparro, A. A. (2002). Cultura Política y Perdón. Bogotá: Universidad del Rosario

Castaño, O. Román. (2016). Injusticia de la justicia. La repentina muerte de la democracia y el Estado de derecho en Colombia. Medellín: Léanlo.

Coates, K. y Jiménez, F. (2009). Programa de Remesas. Remesas internacionales en El Salvador. México: Banco Interamericano de Desarrollo. Centro de Estudios Monetarios. Fondo Multilateral de Inversiones.

COLPRENSA. (5/26/2013). "Comunicado sobre el acuerdo del primer punto de los diálogos de paz”. Cali, Valle: Diario noticioso El País.com.co. <http://www.elpais.com.co/elpais/judicial/noticias/lea-comunicado-sobre-acuerdo-primer-punto-dialogos-paz>

Cotrina Acosta, Andrés (Compilador). (2013). Procesos de paz: un referente, Irlanda del Norte. Universidad Militar Nueva Granada: Serie Informativo. UMNG-IEGAP \#141. Instituto de Estudios Geoestratégicos y Asuntos Políticos. <http://www.iegap-unimilitar.edu.co/images/docs/info141\%20 procesos\%20de\%2opaz.\%20un\%2oreferente\%20irlanda\%20del\%2onorte.pdf>

DANE. (2015). Gran Encuesta Integrada de Hogares (GEIH) 2014. Bogotá: DANE.

Decreto Ley 903. (2017). Por el cual se dictan disposiciones sobre la realización de un inventario de los bienes y activos a disposición de las FARC EP. Bogotá: Presidencia de la República. 
El Tiempo. (09/03/2016). "Aprueban por unanimidad reforma de la Ley de Orden Público”. Bogotá, Colombia: Diario informativo El Tiempo, Sección Política.

Estatuto de Roma de la Corte Penal Internacional. (2002). Roma-Italia: Secretaría General de las Naciones Unidas. Corte Penal Internacional. <http:// www.un.org/spanish/law/icc/statute/spanish/rome_statute(s).pdf>

Fernández, García Jesús. (2002). El proceso de paz de El Salvador diez años después a través de la prensa salvadoreña. Grupo de Investigación de Historia Actual -GEBC (PAI-HUM 315) Universidad de Cádiz. II Seminario Internacional Nuestro Patrimonio Común, Cádiz (España), 22 - 25 de abril de 2002.

Fisas, Vicens. (2010). El proceso de paz en el país Vasco. Barcelona, España: Escola de Cultura de Pau. Quaderns de Construcció de Pau, No 16. <http:// escolapau.uab.es/img/qcp/procesos_paz_pais_vasco.pdf>

Fisk, Milton. (2004). Bienes públicos y justicia radical. Una moralidad política para la resistencia solidaria. Cali, Colombia. Universidad del Valle. Colección Arte y Humanidades.

Guáqueta, A. (2007). "The Way Back in: Reintegrating Illegal Armed Groups in Colombia Then and now". London: Routledge

Hauser, Marc. D. (2008). La mente moral. ¿Cómo la naturaleza ha desarrollado nuestro sentido del bien y del mal. España: Paidós

Herrera, J.C. (2005). "Reconciliación y Justicia Transicional: Opciones de Justicia, Verdad, Reparación y Perdón”, Bogotá: Papel Político, No 18, Diciembre, pp. 79-112

Humanas Colombia. (2009-2016). Cronología de los diálogos de paz. Centro Regional de Derechos Humanos y Justicia de Género. Bogotá: Humanas Colombia. <http://www.humanas.org.co/pagina.php?p_a=82> consultada el 10 de enero de 2016.

Human Rights Watch. (21/12/2015). Análisis del "Acuerdo sobre las Víctimas del Conflicto" alcanzado por el gobierno de Colombia y las FARC. $<$ https:// www.hrw.org/es/news/2015/12/21/analisis-de-human-rights-watch-sobre-el-acuerdo-sobre-las-victimas-del-conflicto>

Kaplow. L. \& Shavell. S. (2002). Fairness versus Welfare. London, Cambridge: Harvard University press.

Los Convenios de Ginebra. (1949). Suiza. Comité Internacional de la Cruz Roja. < <https://www.icrc.org/spa/assets/files/publications/convenios-gva-esp-2012.pdf>

Merino, Mauricio (compilador). (2010). Ética Pública. Buenos Aires, Argentina: Siglo XXI. Biblioteca Básica de Administración Pública.

Mill, Stuart John. (2002). El Utilitarismo. Madrid, España. Filosofía: Alianza Editorial. Introducción, traducción y notas de Esperanza Guisán. 
Mill, Stuart John and Taylor Mill, Harriet. (2001). Ensayos sobre la igualdad sexual. Madrid -España: Ediciones Cátedra. Universidad de Valencia. Introducción de Neus Campillo.

Muñoz Cardona, Á. E. (2010). Introducción a la economía: una visión social y del emprendimiento. Medellín: Ude@. Universidad de Antioquia. Facultad de Ingeniería.

Muñoz Cardona, Á. E. (2014). "The New Public Management in Sabaneta, Antioquia". Open Journal in Political Science, Vol. 4 and No. 3, p.p. 180194. <http://www.scirp.org/journal/PaperInformation.aspx?Paper$\mathrm{ID}=48453>$

Muñoz Cardona, Á.E. (2015). Ética de la responsabilidad ciudadana: un camino para la paz. Medellín: Icolven. Trabajo de investigación Post-Doctoral, Vrije Univerisiteit Amsterdam. NUFFIC.

Ospina, María Clara. (23/12/2015). "Motivos para celebrar en esta navidad". Medellín: Diario El Colombiano. Opinión. <http://www.elcolombiano.com/opinion/columnistas/motivos-para-celebrar-en-esta-navidad-BX3330726>

Ospina, María Clara. (20/05/2015). “¿Dónde están los secuestrados?” Medellín: Diario El Colombiano. <http://www.elcolombiano.com/donde-estan-los-secuestrados-CN1953206>

Ospina, William. (13/02/2016). "Los recursos de la paz". Bogotá: El Espectador, Especial. <http://www.elespectador.com/noticias/paz/los-recursos-de-paz-articulo-616416>

Ospina, William. (12/9/2015). “La guerra de las guerras”. Bogotá: El Espectador, Opinión. <http://www.elespectador.com/opinion/guerra-de-guerras>

Revista Semana. (15/03/2016). "El sitio por donde se 'paseó' la guerrilla en la Guajira”. Bogotá: El Tiempo, Sección: Nación. <http://www.semana.com/ nacion/articulo/reunion-de-los-jefes-de-las-farc-fue-en-el-corregimiento-del-conejo-la-guajira/461080>

Reynaers, Anne-Marie. (2014). Public-Private Partnerships and their Impact on Public Values. Netherlands, Holland: Drukkerij Grafic Image.

Rose-Ackerman, Susan. (2010). "Economía Política de las raíces de la corrupción: investigación y políticas públicas”. En Ética Pública, Mauricio Merino (compilador).Buenos Aires, Argentina: Siglo XXI. P.p. 132-158.

Salgar Antolinez, Daniel. (15/o8/2015). "Los errores de El Salvador en sus acuerdos de paz”. Bogotá: Diario El Espectador.

Skelcher, Chris., Mathur, Navdeep and Smith, Mike. (2005). "The Public Governance of Collaborative Spaces: Discourse, Design and Democracy". Public Administration 83(3), p.p. 573-596

Smith, Adam. (1997). Teoría de los sentimientos morales. Madrid: Alianza Editorial. Estudio preliminar de Carlos Rodríguez Braun. 
Smith, Adam. (1996). Lecciones de Jurisprudencia. Madrid. Imprenta Nacional del Boletín Oficial del Estado. Clásicos Políticos. Traducción y Estudio preliminar de Alfonso Ruíz Miguel.

Smith, Adam. (1995). Lecciones Sobre Jurisprudencia. Granada, España. Biblioteca Comares de Ciencia Jurídica, Colección los Argonautas No 1.

Smith, Adam. (1978). Teoría de los Sentimientos Morales. México. Fondo de Cultura Económica, Introducción por Eduardo Nicol.

Stigliz, Joseph. E. (2002). La economía del sector público. España: Antoni Bosch. Tercera edición.

Troyer, John. (2003). The Classical Utilitarians. Bentham and Mill. United States of America: Edited, with Introduction by John Troyer.

Ángel Emilio Muñoz Cardona Escuela Superior de Administración Pública de Medellín-Antioquia, Colombia e-mail: <angel@esap.gov.co> 